\section{Designs for living}

\section{Paul Crowther}

What Is Art For? By Ellen Dissanayake. University of Washington Press: 1988. Pp.249. \$20. Available in the United Kingdom from Trevor Brown Associates.

Questions about the nature and function of art have traditionally been regarded as the special province of the aesthetician and art historian. Aestheticians, for example, have frequently sought to define art on the basis of phenomenal properties held in common by all artworks. But although they have indeed clarified the complexity of the problem, they have not, as yet, offered anything like a definitive solution.

Dissanayake's project, then, is to discover whether that which is essential and distinctive to art might be more accessible to definition on the basis of a 'biobehavioural', ethological approach that is, one which asks questions such as 'What is art for?' and 'What role does it play in the evolution of our species?'. That art does have such a role is, at first sight, tenable - for despite enormous differences in patterns of practice or execution, at least one or other of the arts (be it dancing, singing, carving, decorating, music-making or versifying) is found universally in every known human grouping, present or past. So there are good grounds for postulating an 'evolutionary reason' for its persistence and ubiquity.

Dissanayake explores this idea by discussing various art practices in contexts ranging from analogues in the animal world, and their function in the psychological development of children, to their social role in palaeolithic and 'primitive' societies and their aesthetic significance in the modern world. In particular, she carefully acknowledges and avoids the problems of a Eurocentric bias, which would favour emphasizing art's aesthetic function over its many other roles.

The result of this approach is the claim that what characterizes behaviour as artistic is the practice or recognition of 'making special'. This is not mere making or creating. As Dissanayake puts it: "Making special implies intent or deliberativeness. When shaping or giving artistic expression to an idea, or embellishing an object, or recognizing that an idea or object is artistic, one gives (or acknowledges) a specialness that without one's activity or regard would not exist. Moreover, one intends by making special to place the activity or artefact in a 'realm' different from the everyday". The ethological significance of this practice is that when it is allied to 'life-serving' activities such as ceremony or tool-making, it consolidates and reinforces their value in a way which enhances 'survivorship'.

The odd thing about Dissanayake's discussion is that it does not solve the problem which she takes herself to be addressing at the start of her book - that of providing a compelling definition of art. The reason is that although 'making special' is (on her terms) a necessary condition of art, it is not a sufficient one; play and ritual also share the same quality. She herself faults the rival approach of philosophical aesthetics for (among other things) attempting to define art in terms of features which turn out to be shared by things besides art. Yet that is just where Dissanayake's own

\section{Full of energy}

\section{A.W. Wolfendale}

Cosmic Rays: Tracking Particles from Outer Space. By Michael W. Friedlander. Hanvard University Press:1989. Pp.160. $\$ 27.50, £ 21.95$

OuR information about the cosmos comes from studies of both matter and radiation, the first being in the form of meteorites and the mis-named cosmic radiation, that rain of high-energy nuclear particles beating down on the top of the Earth's atmosphere. Cosmic Rays is a semipopular account of some of the more important features of these enigmatic particles.

Friedlander's historical introduction is very good, as are his discussions of the relationship of the subject to the fields of high-energy physics and geophysics. The attempt to describe the link with astrophysics proper is disappointing, though, particularly with respect to the outstanding problem of cosmic-ray origin. We are led to believe, from the publisher's blurb and list of contents, that a serious effort will be made to tackle this question; unfortunately, it falls short of expectations.

The most dramatic feature of cosmic rays is the presence of particles as high in energy as $10^{20} \mathrm{eV}$. The origin of these particles is of the utmost interest, but this area receives very sketchy treatment. A dated spectrum shows no features from $10^{16}$ to $10^{20} \mathrm{eV}$, whereas it has been known for some years that there is structure in this range. Mention is made of "a suggestion" of a change in spectral shape above $10^{19} \mathrm{eV}$, but what was needed was a detailed treatment of this region. What are the directions of the particles? If extragalactic in origin, where have they come from? How do they propagate through the ubiquitous microwave background radiation in extragalactic space? These are some of the questions that should have been posed. argument breaks down.

Despite this and some other philosophical worries about the book, Dissanayake's contention that art has ethological significance is itself plausible. Indeed, What Is Art For? is probably one of the most intellectually enriching interdisciplinary studies of art that has ever been written. It combines breadth of learning with lucidity of thought and expression, in a way that should engage the interest of anyone with a systematic interest in the arts - be it scientific, or from the viewpoint of the humanities.

Paul Crowther is a Lecturer in the Department of Art History, University of St Andrews, College Gate, St Andrews, KY16 9AL, UK.

Turning to lower energies, the possibility of particles being accelerated by supernova shocks is mentioned, but it would have been useful to see the evidence set out. Indeed, gamma-ray astronomy - a growth area of cosmic-ray physics - receives scant mention, which is a pity because many of the clues for the origin of the bulk of cosmic rays are coming from this field.

This lack of sensitivity for contemporary astrophysics leads Friedlander to write in his penultimate paragraph.

the history of science has shown how research fields flourish and then dwindle as new fields emerge. It may be that the contributions of cosmic ray research have for the present been exhausted. Those of us who have had the good fortune to participate in this research have had so much enjoyment that we should not begrudge others the excitement of seeing their fields prosper and move ahead.

I have news for the author. Cosmic-ray physics is alive and well. It is to be found in the giant extensive air-shower arrays running and under construction; in the great neutrino detectors; in the gammaray observatory to be launched into orbit later this year; and in the sophisticated detectors being designed to measure the isotopic composition of the cosmic rays and to search for particles of anti-matter in experiments in space and elsewhere.

A.W. Wolfendale is a Professor in the Department of Physics, University of Durham, South Road, Durham DH1 3LE, UK.

\section{New in paperback}

- The Cambridge Guide to the Material World by Rodney Cotterill (Cambridge University Press, £14.95, \$27.95- a snip at the price). For review see Nature 314, 686 (1985)

- Sewall Wright and Evolutionary Biology by William B. Provine (University of Chicago Press, $\$ 18.95, £ 14.25)$. For review see Nature, 324, 175 (1986).

- Darkness at Night: A Riddle of the Universe by Edward Harrison (Harvard University Press, $\$ 12.95, £ 10.25)$. For revicw see Nature 330, 288 (1987).

- Statistics for Nuclear and Particle Physicists by Louis Lyons (Cambridge University Press. £10.95, \$19.95). For review see Nature 325, 586 (1987).

NATURE · VOL 340 - 6 JULY 1989 